\title{
The Failures of Some Will Affect All
}

\author{
J. T. Trevors • M. H. Saier Jr.
}

Received: 19 May 2009 / Accepted: 20 May 2009/Published online: 31 May 2009

(C) Springer Science + Business Media B.V. 2009

Human beings never start their lives as cynics, full of denial and wishful thinking. Everything humans have invented and manufactured is the product of our imaginations. Some discoveries are deemed good, while some may be of lesser value. However, all have their beneficial and detrimental consequences, the latter sometimes being discovered only after years or decades after the invention has been applied. And members of our current societies still have some nasty habits, retained from our evolutionary past when the needs of the population were entirely different from those that concern us today. We are animals with animalistic natures, as well as intellectual beings. In fact, humans continue to organize themselves in strategic and complex ways with the primary purpose of killing, robbing, or cheating other humans and other species of what is "rightfully" theirs. So many examples come to mind. These include the injustices afforded the native Americans during the early expansion of the USA, the illegal and dishonorable

J. T. Trevors $(\bowtie)$

Department of Environmental Biology,

University of Guelph,

Guelph, ON, Canada NIG 2W1

e-mail: jtrevors@uoguelph.ca

M. H. Saier Jr.

Division of Biological Sciences, University of California, San Diego,

La Jolla, CA 92093-0116, USA acquisition of Texas and California from Mexico, the treatment of South American countries when they acted on their own behalf rather than in the interests of the USA, and so on. Many other countries have equally shady pasts. Few of us are proud of these past actions. In fact, the failures of some individuals and countries have been the cause of an immense human suffering and premature death. Collectively, our species has managed to fail to varying degrees in most human endeavors, particularly those that require moral action with respect for the rights of others.

We currently recognize the tragic environmental transformations our planet is undergoing. We know that humans are the cause, and we have solutions to many of these gaping problems. However, we have consistently demonstrated an inability to solve these and future problems. We see them as a bother rather than as a challenge. Worse, we fail to correct the errors of the past even when we know what needs to be done. Thus, for example, we have not yet made serious attempts to implement universal human rights, and practically no funds have been provided for this purpose. We have also failed to control human birth rates, giving rise to the tremendous problems that result from too many people living unsustainable lives. We have failed to implement actions that could decrease pollution of our biosphere and control emissions causing global warming. Politicians and many other individuals have failed to place individual human rights above the state. In spite of our rhetoric, 
we have failed to promote the evolution of modern democracies. There have been failures of knowledge, of will, and of proper action. In fact, people in positions of responsibility have designed and corrupted systems of local and global economies to promote self-advancement. Even in some of our richest developed countries, we have failed to deliver to citizens universal education, although everyone would clearly benefit. We have failed to halt violence and conflicts, thus causing immense resource depletion. We have failed to halt racism, intolerance, and discrimination and consequently have perpetrated social unrest. Yet, we have succeeded to perpetuate activities that marginalize people, overpopulate the planet, and pollute. Since efforts to correct these errors have been inadequate, there is no immediate solution in sight.

Those of us who have lived at least for the past four or five decades have some first-hand experience concerning the deleterious environmental changes humans are causing. Still, even younger generations, the students in our high schools, colleges, and universities, can understand the consequences of a human population out of control which does not practice restraint. Even within the past decade, careful students of the environment can observe the consequences of our actions without turning to the experience of their elders for an overview. How can one not understand the magnitude and impact of global climate change? How can anyone not recognize the consequences of the human population growth crises? More human lives are devalued, demoralized, and degraded everyday as more people are added to our global population. When it is realized that the increase (births over deaths) is 2.3 people per second, or the entire population of North America every 3 years; there cannot be a person anywhere who will not stop in their tracks and agree: THIS CANNOT CONTINUE. Even worse, we know that the situation cannot improve as long as we continue acting as if nothing has happened, as if there is no crisis, as though we think there is still time. What we are presently doing to our planet is almost certainly irreversible, and according to the best scientific knowledge, phenomena such as global warming will continue to get worse for at least one to two centuries after we have stopped net carbon dioxide production. In fact, there is no evidence that our species is going to be intelligent enough to solve this problem. We have no basis for believing that the conditions will improve. Given this situation, for the environmentalist who recognizes the problem, anger, even outrage may be the appropriate response.

In the early industrial age of manufacturing, more products were made than people could possibly use. However, since concerns about resource depletion had not yet surfaced and the number of people on Earth were much lower than at present, there was still no appreciation of the planetary damage resulting. Further, the amount of waste was much less than now, assuming that waste was proportional to the population (an assumption that is certainly not strictly accurate). Today, we have a tremendously excessive human population, and the wastage overall per person is probably much greater. This resulted in part from our consumer mentality, promoted by advertising, and by the advancement of technology, which additionally requires increased dependency on resources such as energy and materials. We certainly do not need more consumers, and we certainly do not need more workers to toil away at industrial production; what we need is the opposite. We need a mentality that recognizes our precarious situation and the consequences of our actions coupled to concern for our young people and the future generations. We need to develop, especially among our most powerful industrialists and politicians, a different mentality. We need to strive toward a caring and compassionate world society. The value of a human being should never be belittled, but it must also be put into perspective with respect to the biosphere. Without a balanced biosphere, the human is nothing and cannot survive. This means that we must develop not only compassion for other people but also for other organisms - all that comprise balanced ecosystems. Thus, the value of a human must be fit into the larger picture of life on Earth. Although we might want a means to measure these relative values, this may prove impossible because of the complexity of the system.

In the past, millions of people were exploited for their physical labor skills. These people simply sold their labor skills to companies. This created inequality of wealth and social unrest. A manufacturing strategy based on mass production only succeeded because there was mass consumption and unrelenting marketing/ advertising. Consume, consume, consume, and then consume more. But mass consumption equates to global pollution. For decades in North America and the older 
industrialized cities of Europe, profits for a few were the only goal. This is no longer a tenable goal. Some cities commenced deindustrialization several years ago, recognizing that such actions were necessary to insure quality of life. But as industrial jobs disappear, other types of jobs must become available. We must emphasize positions such as those of teachers, artists, environmental scientists, and, above all, responsible politicians who truly represent their constituencies. If this plan is not taken, jobless, unoccupied, poor people will continue to turn to lawlessness and crime. They will, perhaps rightfully, do anything to prevent their own suffering and premature deaths. Every form of social damage could result, for example, in the form of selling illegal drugs and imposing addiction on others for profit. This is an economic solution none of us would hope for. And the war on illegal drugs will never be won unless the people have opportunities - opportunities for meaningful education and professions that are satisfying and enjoyable. Otherwise, we are likely to merely fill prisons, prisons that will be full of disgruntled citizens, generate even more dissatisfaction, cost the tax payer enormously, and eventually lead to more conflicts. In many countries, prisons cost more than the educational systems. Such a situation represents the symptoms of a diseased society. Only with an enlightened program of social education can we hope to approach equality without conflict.

How can humans be convinced that our failures surround us and that our successes have not even begun to outnumber the failures? Some will argue that we need more time, but the counter argument is we simply do not have the luxury of an extended period in which we can delay. We lack the time required for compromises and the debate of alternatives as means to solve the immense problems of overpopulation and global climate change. Some of us hope for natural solutions, relying on wishful thinking, others are just in denial, and still others refuse or do not care enough to think about these problems. Procrastination, seldom a practical solution, seems (but only seems) to work best for these people. As we write this editorial, we expect that very few, if any, humans will meet the climate change crisis and prevail. Our optimists have probably not moved a city of ten million or constructed massive dikes in advance of rising sea levels. They have not dealt with massive pandemics or the consequences of resource depletion: thirst and starvation. In spite of their optimism, their offspring will not be able to live a "good" life of waste as their parents and grandparents did, and so much the better. Although the future is always a bit of an enigma, our scientific predictive methods are already sufficiently reliable to allow us to claim with near certainty that change will come, whether by choice or by necessity.

Harsh realities confront humans. Firstly, there are too many humans; our numbers must be reduced as soon as possible, and universal birth control will be absolutely essential if Homo sapiens are to survive. Secondly, we do not WANT to merely survive; we desire to maintain ourselves as groups of independence-minded, freedomloving, quality-demanding communities. Thirdly, global warming, and various forms of pollution, which cause both foreseen and unforeseen problems, must be addressed and solutions must be found. We are not at all prepared to deal with these issues, and progress is way too slow. We need to take care of the problems we currently recognize so that we are prepared to solve those about which we still have no inkling. How will we deal with new issues that will soon confront us if we have not solved the currently recognized crises? We argue that immediate corrective solutions are required. We suspect that drug dealers and other "capitalists at the fringes of society" will not have the answers. We need leadership, and everyone must learn to be a responsible leader. We also need to put into practice the new, equitable, green economy, an economy that will prevent the affluent from continuing living high on the hog at the expense of others. While we must abandon our current hydrocarbon economy, that will only be a beginning. If this crisis of our planet is the dream, a nightmare, it is time to wake up and act. We must ask ourselves, seriously and consciously, why we have allowed ourselves to sleep, what needs to be accomplished, and how it should be done. 